\title{
A new high-transmission inlet for the Caltech nano-RDMA for size distribution measurements of sub-3 nm ions at ambient concentrations
}

\author{
Alessandro Franchin ${ }^{1}$, Andy Downard ${ }^{2}$, Juha Kangasluoma ${ }^{1}$, Tuomo Nieminen ${ }^{1,3,7}$, Katrianne Lehtipalo ${ }^{1,4, a}$, \\ Gerhard Steiner $^{5,6}$, Hanna E. Manninen ${ }^{1}$, Tuukka Petäjä ${ }^{1}$, Richard C. Flagan ${ }^{2}$, and Markku Kulmala ${ }^{1}$ \\ ${ }^{1}$ Department of Physics, University of Helsinki, P.O. Box 64, 00014 Helsinki, Finland \\ ${ }^{2}$ Division of Chemistry and Chemical Engineering, California Institute of Technology, 1200 E. California Blvd., \\ Pasadena, CA, USA \\ ${ }^{3}$ Helsinki Institute of Physics, University of Helsinki, P.O. Box 64, 00014 Helsinki, Finland \\ ${ }^{4}$ Airmodus Ltd, Gustaf Hällströmin katu 2, 00560 Helsinki, Finland \\ ${ }^{5}$ Faculty of Physics, University of Vienna, Boltzmanngasse 5, 1090 Vienna, Austria \\ ${ }^{6}$ Institute of Ion Physics and Applied Physics, University of Innsbruck, Technikerstraße 25, \\ 6020 Innsbruck, Austria \\ ${ }^{7}$ Department of Applied Physics, University of Eastern Finland, P.O. Box 1627, 70211 Kuopio, Finland \\ ${ }^{a}$ currently at: Paul Scherrer Institute, 5232 Villigen PSI, Switzerland
}

Correspondence to: Alessandro Franchin (alessandro.franchin@ @elsinki.fi)

Received: 17 February 2015 - Published in Atmos. Meas. Tech. Discuss.: 15 June 2015

Revised: 23 March 2016 - Accepted: 30 May 2016 - Published: 29 June 2016

\begin{abstract}
Reliable and reproducible measurements of atmospheric aerosol particle number size distributions below $10 \mathrm{~nm}$ require optimized classification instruments with high particle transmission efficiency. Almost all differential mobility analyzers (DMAs) have an unfavorable potential gradient at the outlet (e.g., long column, Vienna type) or at the inlet (nano-radial DMA), preventing them from achieving a good transmission efficiency for the smallest nanoparticles. We developed a new high-transmission inlet for the Caltech nano-radial DMA (nRDMA) that increases the transmission efficiency to $12 \%$ for ions as small as $1.3 \mathrm{~nm}$ in MillikanFuchs mobility equivalent diameter, $D_{\mathrm{p}}$ (corresponding to $1.2 \times 10^{-4} \mathrm{~m}^{2} \mathrm{~V}^{-1} \mathrm{~s}^{-1}$ in electrical mobility). We successfully deployed the nRDMA, equipped with the new inlet, in chamber measurements, using a particle size magnifier (PSM) and as a booster a condensation particle counter (CPC). With this setup, we were able to measure size distributions of ions within a mobility range from $1.2 \times 10^{-4}$ to $5.8 \times 10^{-6} \mathrm{~m}^{2} \mathrm{~V}^{-1} \mathrm{~s}^{-1}$. The system was modeled, tested in the laboratory and used to measure negative ions at ambient concentrations in the CLOUD (Cosmics Leaving Outdoor Droplets) 7 measurement campaign at CERN. We achieved a
\end{abstract}

higher size resolution $\left(R=5.5\right.$ at $\left.D_{\mathrm{p}}=1.47 \mathrm{~nm}\right)$ than techniques currently used in field measurements (e.g., Neutral cluster and Air Ion Spectrometer (NAIS), which has a $R \sim 2$ at largest sizes, and $R \sim 1.8$ at $D_{\mathrm{p}}=1.5 \mathrm{~nm}$ ) and maintained a good total transmission efficiency $\left(6.3 \%\right.$ at $\left.D_{\mathrm{p}}=1.5 \mathrm{~nm}\right)$ at moderate inlet and sheath airflows $\left(2.5\right.$ and $30 \mathrm{~L} \mathrm{~min}^{-1}$, respectively). In this paper, by measuring size distributions at high size resolution down to $1.3 \mathrm{~nm}$, we extend the limit of the current technology. The current setup is limited to ion measurements. However, we envision that future research focused on the charging mechanisms could extend the technique to measure neutral aerosol particles as well, so that it will be possible to measure size distributions of ambient aerosols from $1 \mathrm{~nm}$ to $1 \mu \mathrm{m}$. 


\section{Introduction}

Aerosol particles are an active subject of research because of their impact on climate (Paasonen et al., 2013; IPCC, 2013) and human health (Mauderly and Chow, 2008; Rohr and Wyzga, 2012), and because of their potential in the synthesis of new materials (Banin et al., 2013; Schauermann et al., 2012). Recent technological developments have allowed measurements of smaller and smaller particles (e.g., Jiang et al., 2011c; Vanhanen et al., 2011; Kulmala et al., 2012). One of the driving forces for these developments has been the need to understand atmospheric aerosol formation (Kulmala et al., 2007; Kirkby et al., 2011; Kulmala et al., 2013; Siingh et al., 2013; Kamra et al., 2015), a process that has been identified as one of the most important sources of aerosol particles in the atmosphere (Spracklen et al., 2008; Merikanto et al., 2009).

The crucial size range in understanding the details of aerosol formation is from 1 to $3 \mathrm{~nm}$. This is the size range of the new clusters, either neutral or charged, that are formed by the collision of precursor vapor molecules such as sulfuric acid (Sipilä et al., 2010), ammonia (Kirkby et al., 2011), amines (Petäjä et al., 2011; Almeida et al., 2013) and organic precursors (Ehn et al., 2014; Riccobono et al., 2012). The small size of these clusters poses a challenge for their measurement and detection, as they are easily lost by diffusion during sampling and are difficult to charge for electrical classification. On the one hand, their low concentrations hinder the use of an electrometer as the detector. On the other hand, when using condensational techniques for detection, a very high supersaturation is required to grow the particles large enough for optical detection.

A combination of condensation techniques and electrical mobility classification has proven to be an effective method for atmospheric aerosol number distribution measurements (Flagan, 1998; McMurry et al., 2000). In practice, the number size distribution can be measured using a differential mobility analyzer (DMA), which classifies the aerosol by mobility, and a condensation particle counter (CPC), which determines the number concentration. The combination of DMA and CPC is termed differential mobility particle sizer (DMPS) or scanning mobility particle sizer (SMPS), depending on whether the classifying high voltages are stepped or ramped, respectively. When sampling sub- $3 \mathrm{~nm}$ atmospheric particles, ultrafine CPCs do not have high enough detection efficiency to activate and count such small particles, and conventional DMAs do not have adequate transmission efficiency nor the high enough size resolution required to analyze the very first steps of nucleation in the atmosphere.

The DMA measurement range has recently been extended down to $1 \mathrm{~nm}$ through design of new high-resolution DMAs (Rosell-Llompart et al., 1996; Rosser and Fernandez de la Mora, 2005; Steiner et al., 2010; Fernandez de la Mora and Kozlowski, 2013). By coupling these high-resolution DMAs with highly sensitive detectors (particle counters or mass spectrometers), even nanometer-sized molecular clusters can be classified and characterized. Unfortunately, only a tiny fraction of the ions or charged particles entering these instruments reach the detector. This low transmission efficiency limits their use for direct measurement of atmospheric ions. To tackle the low transmission, the University of Tartu developed low-resolution DMAs that have high inlet flow rates. They have successfully used the Air Ion Spectrometer (AIS; Asmi et al., 2009; Gagn'e et al., 2011; Mirme and Mirme, 2013), the Balanced Mobility Scanning Analyzer (BSMA; Tammet, 2006) and the Symmetric Inclined Grid Mobility Analyzer (SIGMA; Tammet, 2011) to measure concentrations and size distributions of ambient ions. These instruments have extremely high inlet flow rates (from 54 to thousands of liters per minute, $\mathrm{L} \mathrm{min}^{-1}$ ), which enable high ion transmission efficiencies (greater than $80 \%$ ) but limit their resolution to $R<2$, where $R$ is defined as the ratio of the mobility of the ion/particle that is transmitted with the greatest efficiency to the range of mobilities for which the transmission efficiency is at least half of that value. Unfortunately, such extreme flow rates also limit the usefulness of these instruments in the laboratory or in chamber studies. With DMA measurements extended into the sub- $3 \mathrm{~nm}$ size range, commercially available CPCs were no longer capable of detecting the size classified particles selected by the DMA. Iida et al. (2009) overcame the inability of the CPC to detect particles smaller than $2.5 \mathrm{~nm}$ by introducing a twostage CPC. Particles are first activated using a high-surfacetension, low-vapor-pressure working fluid that minimizes the risk of homogeneous nucleation at the high supersaturations required to activate $1 \mathrm{~nm}$ particles. The activated droplets are then grown to detectable size using a second, "booster" CPC. Iida et al. (2009) modified a commercial, ultrafine CPC for the first stage, removing the optical detector and feeding the activated particles to a conventional, butanol CPC. Several groups have followed that design (Wimmer et al., 2013), producing instruments that have probed new particle formation to sizes close to that of the critical cluster. However, the low sample flow rates typical of this design lead to poor counting statistics when measuring low concentrations of particles using the CPC as a detector behind a DMA. Vanhanen et al. (2011) - inspired by the work of Okuyama et al. (1984), Seto et al. (1997) and Sgro and Fernandez de la Mora (2004) - developed a two-stage CPC that counts particles in a much larger flow by replacing the laminar flow design of the traditional instruments with a mixing-type activation stage. Moreover, this particle size magnifier (PSM) can rapidly step through a number of supersaturated states and thereby measure the activated particles. These data are used to estimate the size distribution of particles in the 1 to $3 \mathrm{~nm}$ size range, albeit with significant sensitivity to particle composition (Kangasluoma et al., 2013; Lehtipalo et al., 2014). A considerable step forward would be a combination of a PSM with a high-transmission DMA. Such an instru- 
ment would enable reliable sizing that is able to count single particles.

The Caltech nano-radial DMA (nRDMA; Zhang and Flagan, 1996; Brunelli et al., 2009) is a nano-DMA known for its compact design and for its high resolution at relatively low sheath gas flows. Previous studies (Jiang et al., 2011a) showed that the nRDMA has a higher resolving power and a better transmission than other DMA designs operating in the range of 1 to $100 \mathrm{~nm}$. Accordingly, the device shows promise to extend the accessible measurement range for DMAs into the sub-3 nm region. DMAs could provide a measurement technique that would allow a continuous, high-resolution overview of the size distributions, from molecular clusters to aerosol particles.

Jiang et al. (2011b) developed a scanning mobility particle spectrometer (DEG SMPS) for measuring number size distributions of particles down to $\sim 1 \mathrm{~nm}$ mobility diameter. Their DEG SMPS included an aerosol charger, a TSI 3085 nanoDMA, an ultrafine condensation particle counter (UCPC) using diethylene glycol (DEG) as the working fluid and a conventional butanol CPC to detect the small droplets leaving the DEG UCPC. Jiang et al. (2011b) successfully deployed their DEG SMPS in the field (Jiang et al., 2011c) in Atlanta, Georgia, USA, where the concentrations of sub-3 $\mathrm{nm}$ particles exceeded $10^{4} \mathrm{~cm}^{-3}$.

This paper builds upon that foundation in order to measure both charged and neutral aerosol particles in the same size range, but at concentrations lower than $10^{4} \mathrm{~cm}^{-3}$. Measurements of neutral aerosol clusters are not trivial, as standard chargers (for example, radioactive bipolar charger or corona chargers) provide a spectrum of charger ions that goes up to almost $5 \times 10^{-5} \mathrm{~m}^{2} \mathrm{~V}^{-1} \mathrm{~s}^{-1}, \sim 2 \mathrm{~nm}$ in Millikan-Fuchs mobility equivalent diameter (Manninen et al., 2011; Steiner and Reischl, 2012). The charger ions change with air composition, and their size distribution overlaps with that of the aerosol particles that we want to measure. For this reason, our study is limited to ions.

This work continues the work done in the past on preventing the edge disturbances in air ion measurements (Israël, 1970; Tammet, 1970; Labowsky and Fernandez de la Mora, 2006). Here, we introduce and validate a new inlet design that increases the transmission efficiency from a few percent to about $12 \%$ for particles with a mobility diameter of $1.5 \mathrm{~nm}\left(9.7 \times 10^{-5} \mathrm{~m}^{2} \mathrm{~V}^{-1} \mathrm{~s}^{-1}\right.$ in mobility $)$. The high transmission efficiency achieved makes it possible to use the instrument to measure ions at ambient concentration down to $1.3 \mathrm{~nm}\left(1.2 \times 10^{-4} \mathrm{~m}^{2} \mathrm{~V}^{-1} \mathrm{~s}^{-1}\right.$ in mobility). All diameters reported here are Millikan-Fuchs equivalent mobility diameters (Mäkelä et al., 1996). As the diameter is not a welldefined concept at very small sizes, we choose to indicate next to the diameter the particle electrical mobility, which is the measured quantity. We also present a successful application of the nRDMA, combined with a PSM (Airmodus A09), to classify and measure ions, as used during the CLOUD (Cosmics Leaving Outdoor Droplets) 7 campaign in 2012.
The CLOUD aerosol chamber is located at CERN, in Switzerland. It has been used for several aerosol nucleation studies (Kirkby et al., 2011; Almeida et al., 2013; Riccobono et al., 2014). During the CLOUD 7 campaign, a-pinene and sulfuric acid nucleation studies were carried out.

\section{Experimental setup}

\section{1 nRDMA description}

The nRDMA design extends the RDMA design of Zhang et al. (1995) to allow classification of particles in the low nanometer regime (Brunelli et al., 2009). The version of the nRDMA used in this study is the new version of the DMA used in Brunelli et al. (2009). The nRDMA used in this study is a refined version of the first nRDMA. The main difference was an increased diameter in the exhaust pipe line to allow larger sheath flow rates to be used without causing turbulence. Here, we give just a brief description. To visualize the radial design, start from a vertical section of a planar DMA (Fig. 1a). If we rotate the section of the planar DMA around the axis along and parallel to the lower electrode, we obtain a classical cylindrical DMA (Fig. 1b). If we rotate the section along the vertical axis, perpendicular to the electrodes, we obtain a radial DMA (Fig. 1c). The nRDMA consists of two parallel circular plates, one at the top and one at the bottom. These two plates form the electrodes of the classification region. The sheath airflow moves radially from the outside to the center, through the space between the two plates, and it exits from a central hole in the circular plate at the top. The polydisperse aerosol sample enters the top plate tangentially to its outer circumference and reaches the classification region through a circular peripheral slit. After the aerosol enters the classification region, it is driven toward the bottom plate by an electric field. Two factors determine the particle's trajectory: the radial velocity, determined by sheath flow, and the perpendicular velocity, determined by the electric field on the charged particle of mobility $Z$. Classified particles (those within a narrow range of mobilities around the target mobility of $Z$ ) are extracted through an outlet port, which is located at the center of the bottom plate. The classified aerosol is then counted by an electrometer or a CPC. In order to produce the electric field within the nRDMA, the top inlet plate is maintained at high voltage (positive for positively charged particles, negative for negative ones), while the bottom plate is electrically grounded. The inlet flow plumbing that brings the aerosol sample into the DMA is also grounded, introducing an adverse electric field that charged particles must traverse as they enter the DMA. This adverse gradient limits the transmission efficiency. This paper describes the development of a new, high-transmission-efficiency inlet to reduce the impact of this adverse gradient. 
(a)

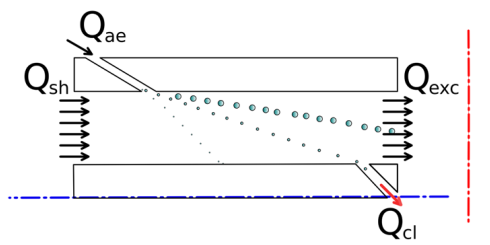

(b)
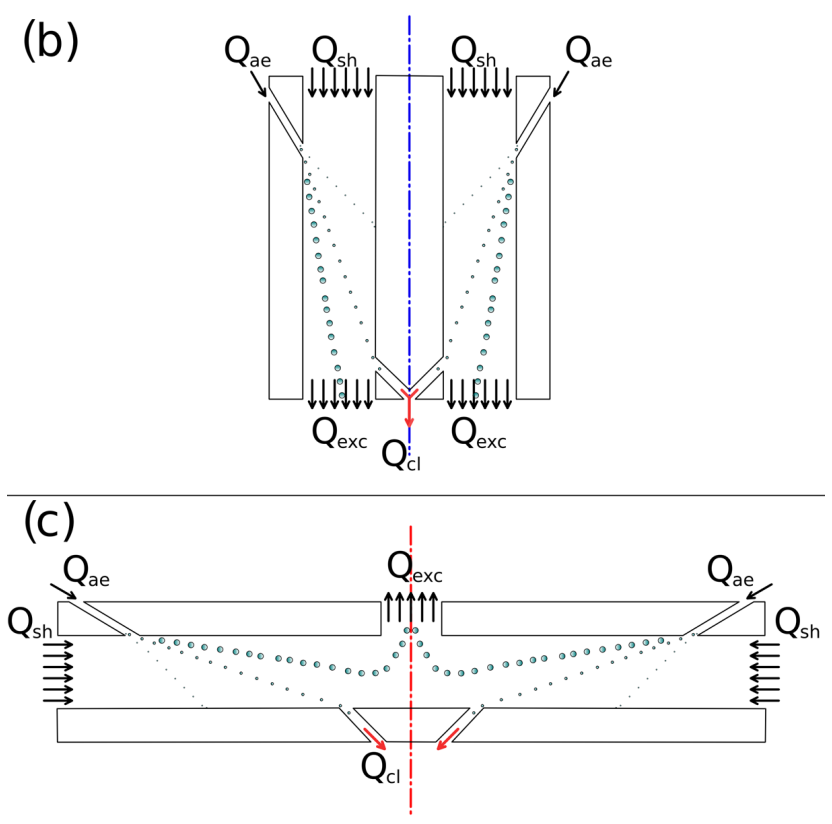

Figure 1. (a) Section of a schematic design of a planar DMA. The sheath gas flow $\left(Q_{\mathrm{sh}}\right)$ enters from the left. The polydisperse aerosol flow $\left(Q_{\mathrm{ae}}\right)$ enters the classification region from a slit at the top left. The classified aerosol $\left(Q_{\mathrm{cl}}\right)$ exits from a slit at the bottom right, and the excess flow $\left(Q_{\text {exc }}\right)$ is discarded at the right, along with the unclassified aerosol. (b) Section of a schematic design of a cylindrical DMA, obtained by turning the section of the planar DMA along its horizontal axis, along the bottom electrode. (c) Section of a schematic design of a radial DMA, obtained by turning the section of the planar DMA along its vertical axis. $Q_{\mathrm{sh}}$ flows radially from the periphery of the classification region, towards the center. $Q_{\mathrm{ae}}$ enters the classification region from a tangential slit at the top. $Q_{\mathrm{cl}}$ exits from the outlet located at the bottom plate. $Q_{\text {exc }}$ is discarded, with the unclassified aerosol, through the outlet at the center of the top electrode.

\subsection{High-transmission inlet description}

As noted above, the need to transition from the grounded sampling line to the high voltage of the inlet creates an adverse gradient that causes charged particles to migrate along the electric field lines and deposit before they enter the classification region. This problem, also known as edge effect (Israël, 1970; Tammet, 1970), is not unique to the nRDMA; Kousaka et al. (1986) described electrostatic losses in the outlet of the TSI DMA and reduced those losses by lining the Teflon insulator at the outlet of the instrument with brass. Zhang and Flagan (1996) applied scaling rules to character- (a)
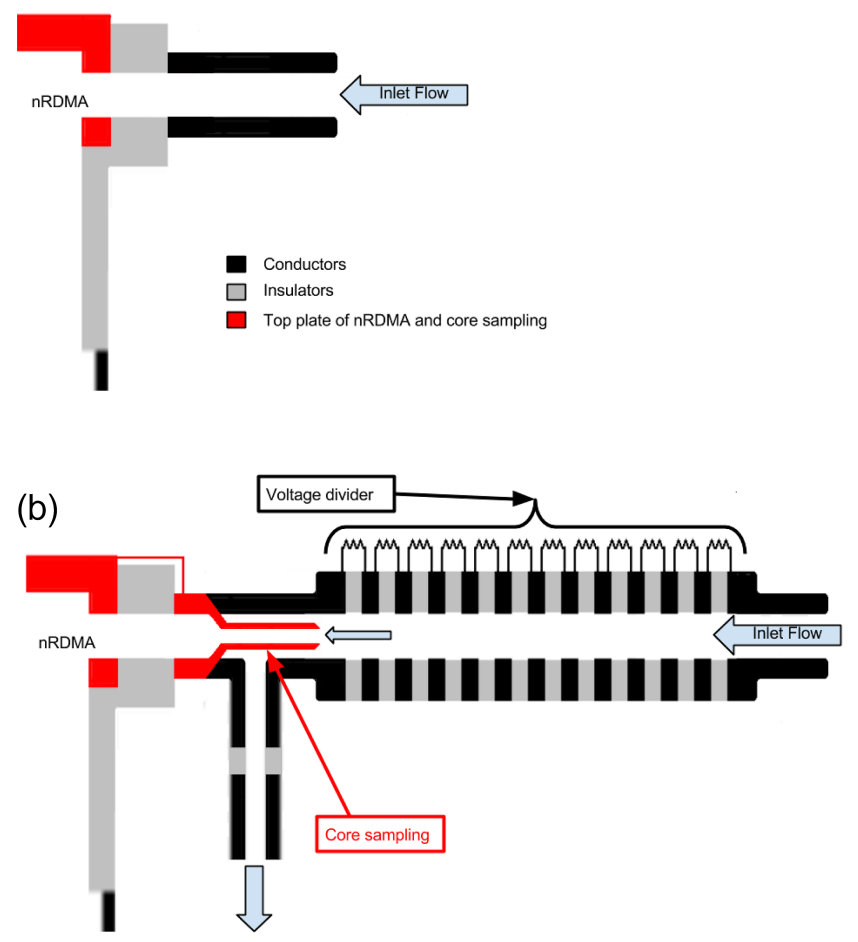

Figure 2. Sketch of the nRDMA inlet. (a) shows the original inlet; (b) shows the high-transmission inlet. Moving from right to left, inlet flow enters from the voltage divider. Thanks to the inlet design, the voltage increases gradually, from ground potential to the potential of the top plate of the nRDMA. In this way, the gradient of the electric potential is decreased so that the drift velocity of the ions, due to the electric field, is small compared to the flow velocity. Before reaching the top plate of the nRDMA, the portion of the inlet flow closer to the walls is discarded, and only the core of the total inlet flow enters the classification region.

ize similar losses at the outlet of the original RDMA. The adverse gradient is a problem that remains inherent to DMAs. While we cannot eliminate it, the present paper describes a novel inlet design that dramatically weakens it. This hightransmission inlet design consists of two parts: a voltage divider and a core sampling probe (Fig. 2b). The voltage divider consists of a set of electrostatic lenses (made of stainless steel) with an inner diameter of $6.35 \mathrm{~mm}(1 / 4 \mathrm{in}$.), an outer diameter of $25.4 \mathrm{~mm}$ ( 1 in.) and a width of $2 \mathrm{~mm}$. The lenses are alternatively stacked with electrically insulating spacer discs $\left(\right.$ Delrin $\left.{ }^{\circledR}\right)$, to form a tube with a total length of $50 \mathrm{~mm}$. Each of the electrostatic lenses is connected to its neighboring lens by a $1 \mathrm{M} \Omega$ resistor. The lens that is furthest away from the nRDMA is connected to ground potential, while the one next to the nRDMA inlet is at the same potential as the top plate of the nRDMA.

The efficacy of the reduced gradient is enhanced by increasing the velocity of the flow that enters the inlet assembly, increasing the velocity such that the induced migration 
away from the nRDMA is overwhelmed. The voltage divider is used to minimize the gradient of the electric potential so that the drift velocity of the ions, due to the electric field, is small compared to the flow velocity, resulting in an improved overall ion transmission efficiency. A core sampling probe withdraws the sample from the center of the voltage divider, away from inhomogeneities of the electric field at the walls. The probe consists of a small tube at the end of the voltage divider, sampling a flow of $2.5 \mathrm{~L} \mathrm{~min}^{-1}$ from the center of the $6.35 \mathrm{~mm}$ inlet tube, which carries the total inlet flow $\left(9 \mathrm{~L} \mathrm{~min}^{-1}\right)$. The remaining airflow is discarded.

\subsection{Electrometer and particle size magnifier}

Two detectors were used with the nRDMA to measure the concentration of the classified aerosol: an electrometer (TSI 3068) and a PSM (Airmodus A09) together with a booster CPC. We used the electrometer in the electrospray experiments, as the generated ion concentrations were high enough $\left(>10^{4} \mathrm{~cm}^{-3}\right)$ to generate a clear signal. In fact, for the electrometer in use, the minimum detectable current $I$ is around $1 \mathrm{fA}$. If the electrometer is operated at $1 \mathrm{~L} \mathrm{~min}^{-1}$ inlet flow rate $(F)$, and the ions carry only one single charge $e$, then the corresponding concentration of ions $N=\frac{I}{\mathrm{Fe}}=374 \mathrm{~cm}^{-3}$. Accounting for the nRDMA's ion transmission efficiency of about $15 \%$, the ion (or charged particle) concentration of a given mobility must be larger than $6000 \mathrm{~cm}^{-3}$. Thus, the electrometer is not suitable for ambient measurements where the total ion concentration is on the order of $1000 \mathrm{~cm}^{-3}$. However, the PSM has the required sensitivity, because of its high counting efficiency ([45-65]\% at $1.3 \mathrm{~nm}$ ).

For measurements at low concentrations, it is important to carefully tune the operation temperatures of the PSM to achieve the lowest possible background counts and to reach the highest particle detection efficiencies. The supersaturation inside the PSM needs to be set close to that at which homogeneous nucleation would occur, in order to push the limit of detection to the lowest possible size. Nonetheless, when operated at optimal conditions, the PSM's background counts are low (only 1-2 counts $\mathrm{min}^{-1}$ ), corresponding to a background concentration of about $10 \mathrm{~cm}^{-3}$. The PSM counting efficiency and low background signal allow measurement of concentrations as low as 60 ions $\mathrm{cm}^{-3}$. When neutral particles are measured, an aerosol charger must be added to the setup, which, in the case of a bipolar charger being used, reduces the signal intensity by about $99.5 \%$, due to the low charging probability at particle sizes $<3 \mathrm{~nm}$ (Wiedensohler, 1988). Thus, even when using a PSM, these measurements remain extremely challenging, unless particle concentrations are on the order of several tens of thousands $\mathrm{cm}^{-3}$.

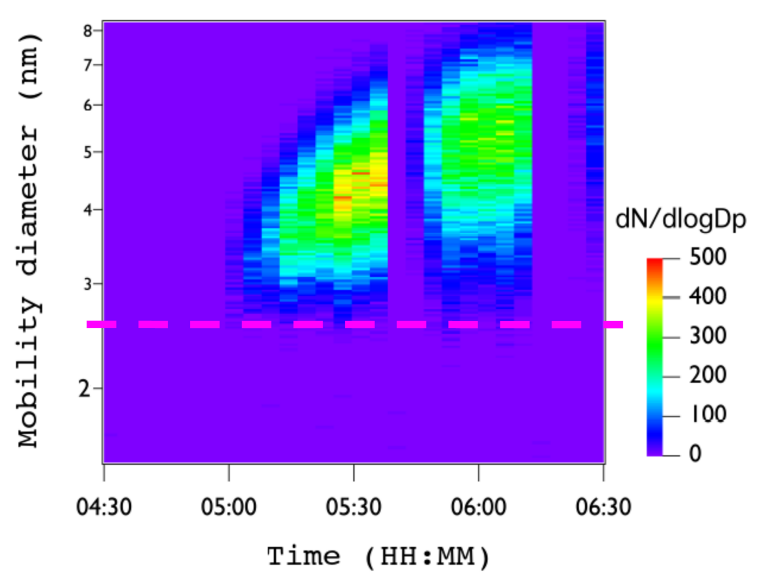

Figure 3. Spectrum of negative ions in the CLOUD aerosol chamber during a nucleation event. The spectrum was measured during the CLOUD 4 campaign, using the nRDMA-PSM system with the old inlet (Fig. 2a). It should be noted that it was not possible to detect particles below about $2.5 \mathrm{~nm}$ (dashed magenta line). The gap in the color plot between 05:30 and 06:00 UTC is due to the electric field inside the CLOUD chamber being switched on, causing all the ions in the chamber to be swept out.

\section{Results and discussion}

The nRDMA-PSM system was first deployed during the CLOUD 4 campaign for chamber experiments at CERN (Kirkby et al., 2011). During the CLOUD 4 campaign, the nRDMA-PSM system was not able to detect particles below $2.5 \mathrm{~nm}$ (Fig. 3). To address this unexpected lack of transmission, a series of laboratory experiments was carried out: electrospray experiments, transfer function determination and field measurements. The electrospray experiments were carried out to characterize the inlet region and were used to derive an inlet design to maximize ion transmission. The transfer function determination was carried out to characterize the DMA's transmission efficiency and resolving power. The field measurements were carried out to prove that it is possible to measure ion-mobility spectra at ambient concentrations. The nRDMA-PSM system with the new inlet design was used during the CLOUD 7 campaign, improving the detection efficiency of ions from 2.5 to $1.3 \mathrm{~nm}$.

\subsection{Electrospray experiments}

Electrospray experiments were carried out to investigate the performance of the inlet region of the nRDMA. These results were used to collect information for the design of the high-transmission-efficiency inlet. For These tests, we used an electrometer (TSI 3068A) to detect the classified ions and a custom-built electrospray source (ES) to generate Tetraheptylammonium ions (THAB) as mobility standards (Ude and Ferandez de la Mora, 2005). The nRDMA was operated with an aerosol inlet flow $\left(Q_{\mathrm{ae}}\right)$ of $2.4 \mathrm{~L} \mathrm{~min}^{-1}$ and a sheath gas 


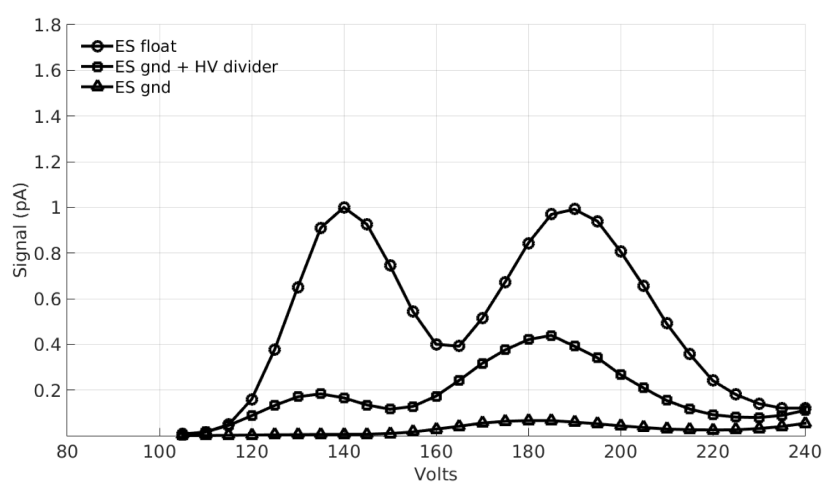

Figure 4. Spectra of electrosprayed THAB solution measured using the nRDMA as a classifier and an electrometer as a counter. The circular markers indicate a spectrum obtained by keeping the potential of the electrospray counter electrode floating. The triangles show a spectrum obtained by grounding the electrospray counter electrode. The spectrum indicated by squares was obtained using the new inlet.

flow $\left(Q_{\mathrm{sh}}\right)$ of $15.7 \mathrm{~L} \mathrm{~min}-1$. When the ES was used with its counter electrode grounded, we observed no signal from the THAB monomer (mobility: $9.71 \times 10^{-5} \mathrm{~m}^{2} \mathrm{~V}^{-1} \mathrm{~s}^{-1}$; equivalent diameter: $1.47 \mathrm{~nm}$ ) and only a small signal from the THAB dimer (mobility: $6.54 \times 10^{-5} \mathrm{~m}^{2} \mathrm{~V}^{-1} \mathrm{~s}^{-1}$; equivalent diameter: $1.78 \mathrm{~nm}$ ). This seems to be in disagreement with the results shown in Brunelli et al. (2009); however, when the potential of the counter electrode was allowed to float, the THAB monomer was detected and the THAB dimer showed a signal increase of more than one order of magnitude (Fig. 4), achieving a signal comparable to the one reported by Brunelli et al. (2009). We related the low transmission efficiency obtained with the grounded ES counter electrode to the low transmission efficiency obtained in the chamber measurements. We attributed this change in transmission to a change in electrostatic losses in the region between the inlet and the top electrode of the nRDMA. In that space, the ions experience a steep adverse potential gradient when the counter electrode of the electrospray is grounded in the same way as in the chamber measurements, where the inlet line is grounded (Fig. 5). The design of the new inlet confirmed our hypothesis. In fact, the new design decreases the slope of the potential gradient, keeping the ES counter electrode grounded and allowing an increase in transmission from 0 to about $12 \%$ for the THAB monomer and from 10 to $50 \%$ for the dimer. This phenomenon can be understood by analyzing the magnitude of $\boldsymbol{v}_{\boldsymbol{E}}$, the drift velocity of the ions due to the electric field, and $\boldsymbol{v}_{f}$, the velocity of the ions due to the carrier flow. $\boldsymbol{v}_{\boldsymbol{E}}=Z \boldsymbol{E}$, where $Z$ is the electrical mobility and $\boldsymbol{E}$ is the electric field. Since the direction of $\boldsymbol{v}_{\boldsymbol{E}}$ is opposed to $\boldsymbol{v}_{\boldsymbol{f}}$, small ions, which have a high mobility, are more easily lost than larger charged particles (Fig. 6).
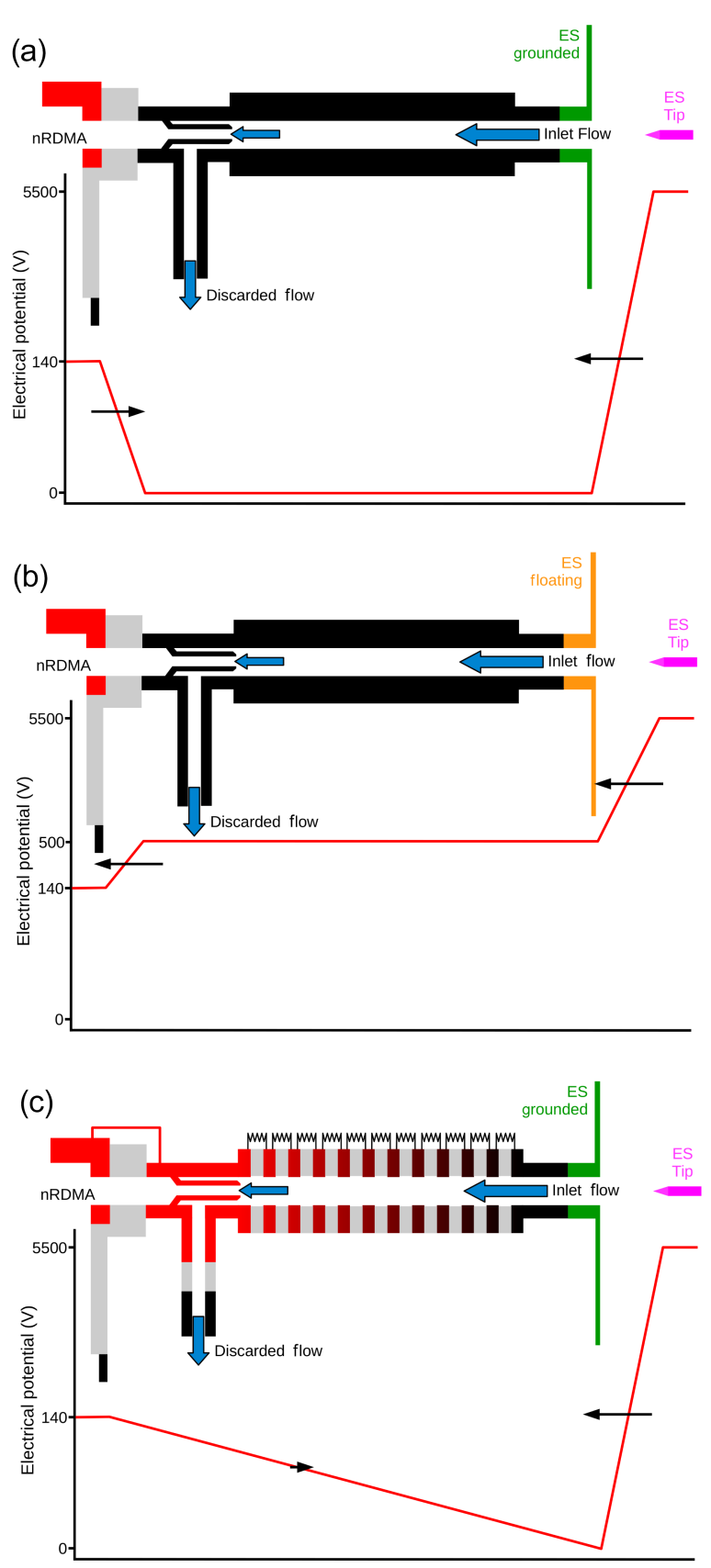

Figure 5. Illustration of the sources and nature of the adverse potential gradient that occurs when the counter electrode of the electrospray is grounded, as in chamber measurements, where the sampling inlet is grounded. The schematics show the setup used for measuring the spectra of THAB ions, along with sketches of the potential gradient present in the nRDMA inlet region. (a) shows the apparatus when the potential of the electrospray counter electrode is grounded and the resulting potential variation along the flow path (red line). The black arrows show the direction of the electric field experienced by the ions. (b) shows the change in electrical potential when the counter electrode of the electrospray is allowed to float. (c) shows the setup with the new inlet. The adverse gradient is drastically reduced by the use of the voltage divider. 


\subsection{Saturation effect}

During the experiments using the ES, we noticed that the signal for the THAB dimer was low and that, if the counter electrode of the electrospray source was kept grounded, no signal corresponding to the THAB monomer was detected. When the counter electrode of the ES was allowed to float, a clear signal for the monomer was observed and the dimer signal increased sixfold. We interpreted this change in transmission as a purely electrostatic effect. The simulation of the electric potential at the nRDMA's inlet shows that, when the ES counter electrode potential is floating, the electric field attracts the ions towards the nRDMA. When the ES counter electrode is grounded, the ions are repelled from the nRDMA's inlet (Fig. 5). We relate the absence of signal below $2.5 \mathrm{~nm}$ during the measurements at the CLOUD chamber to this effect. An interesting question that arises is why, in the work by Jiang et al. (2011a), ions below $3 \mathrm{~nm}$ were detected with a comparable transmission efficiency to that observed with the floating electrospray counter electrode potential. This apparent discrepancy could be the result of a saturation effect (Fig. 7). When the nRDMA inlet is at ground potential (as in the CLOUD experiments), the high potential gradient between the inlet and the top plate repels the ions, pushing them back against the flow and against the walls, thus increasing the losses. When unipolar ions are used, as in Jiang et al. (2011a), we hypothesize that the ions quickly deposit on the walls of the electrical insulator that separates the inlet from the top plate of the nRDMA. This effect is shown in Fig. 7, where unipolar ions (mobility: $8.0 \times 10^{-5} \mathrm{~m}^{2} \mathrm{~V}^{-1} \mathrm{~s}^{-1}$; equivalent diameter: $1.6 \mathrm{~nm}$ ) are sent through a small piece of insulator (inner diameter $4 \mathrm{~mm}$, length $2.5 \mathrm{~cm}$ ), comparable to the one used inside the nRDMA. The concentration of ions was kept constant and was monitored by an electrometer downstream from the insulator and a PSM downstream from the insulator. The fraction of ions seen by the PSM, and therefore the transmission of the insulator piece, changes with time. At the beginning of the experiments no ions are detected by the PSM. After $5 \mathrm{~min}$, the ion concentration saturates at its equilibrium value, in this case around $10 \%$, resulting from a combination of the PSM detection efficiency and the transmission of the insulator that we tested. We speculate that the ions on the walls may create a weak electric field that focuses the ions towards the center of the insulator and reduces ion loss. In the case of a bipolar environment, the insulator's surface is constantly neutralized by the deposition of positive and negative ions, resulting in higher ion losses. Based on the measurements carried out so far, this effect seems to be negligible for mobility diameters bigger than about $3 \mathrm{~nm}$.

Interestingly, we did not observe a saturation effect during our electrospray experiments. Although we did not carry out a dedicated experiment to investigate this effect using the electrospray source, an increase of the transmitted signal would be expected, similarly to how it is observed when

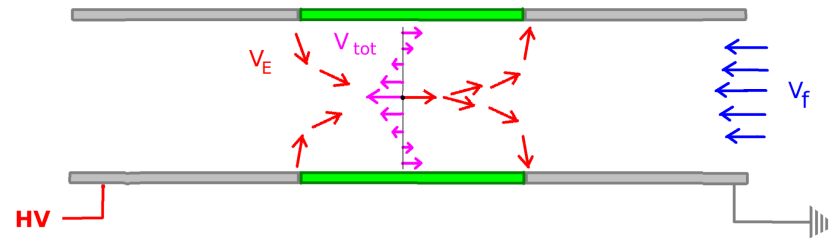

Figure 6. Schematic of the voltage transition at the inlet of the nRDMA. The inlet flow goes from right to left with velocity $\boldsymbol{v}_{\boldsymbol{f}}$. The drift velocity of the ions $\boldsymbol{v}_{\boldsymbol{E}}=Z \boldsymbol{E} . Z$ is the electrical mobility of the ion, and $\boldsymbol{E}$ the electric field generated by the potential difference between the inlet and the top plate of the nRMDA. $v_{f}$ is the velocity of the ions due to the carrier flow. The direction of $\boldsymbol{v}_{\boldsymbol{E}}$ is opposed to $v_{f}$. Therefore, small, high-mobility ions are more easily lost than larger ions or charged particles.

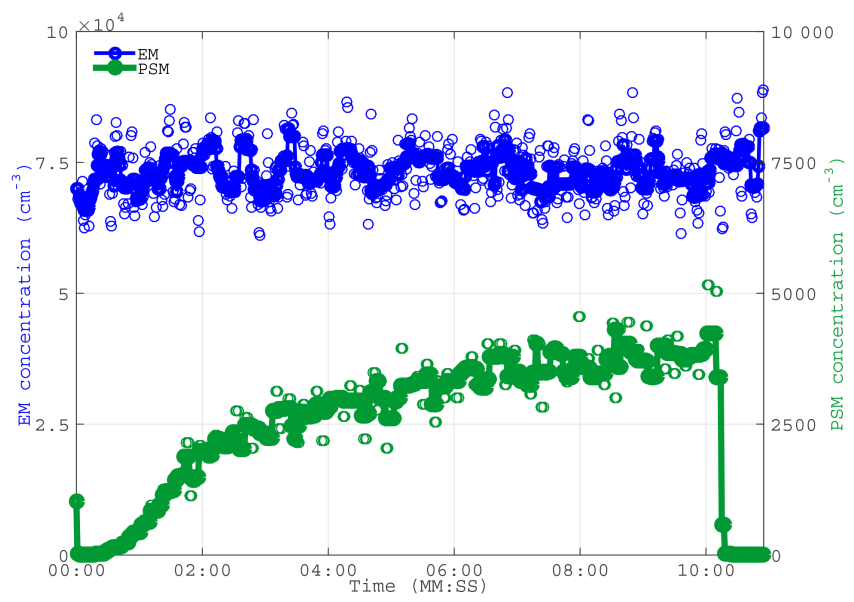

Figure 7. Saturation effect due to the deposition of ions on the inner surface of a Teflon tube. The ions are size-selected and sent through the tube insulator. The PSM is used as a counter downstream of the tube. The transmission for small ions is zero at the beginning and reaches equilibrium after about $10 \mathrm{~min}$. After that, the tube is grounded and the transmission goes back to zero.

using a monodisperse aerosol. Two key differences between the electrospray experiments and other tests performed are (1) the high concentrations of ions (charged particles) produced by the electrospray and (2) the presence of solvent molecules in vaporized form in the aerosol flow. The observed high transmission efficiency and the lack of an observed saturation effect might both result from rapid saturation at high concentrations of charged particles and/or from the effect of the deposition of the solvent molecules onto the walls, which, even though present in trace amount, could change the surface properties of the insulator in the inlet.

\subsection{Transfer function determination}

To determine the transfer functions, we carried out a set of experiments using an ammonium sulfate test aerosol, classified with a high-resolution differential mobility analyzer 


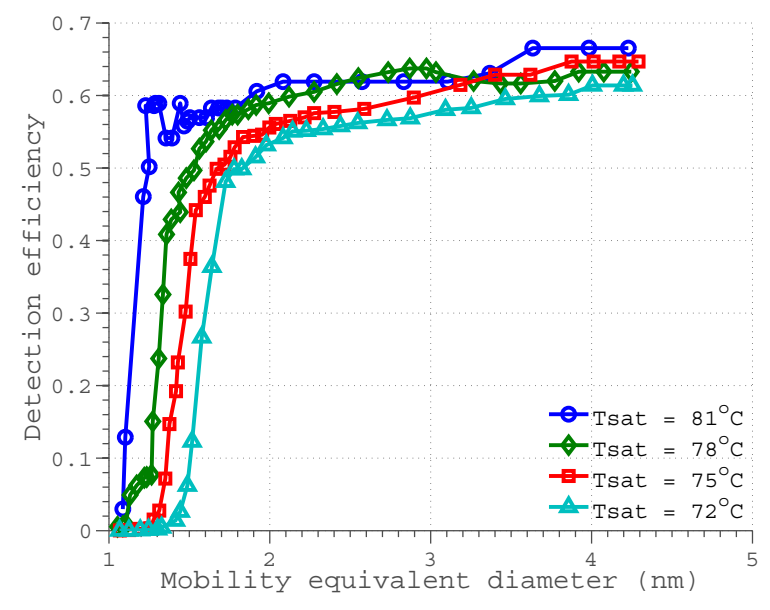

Figure 8. PSM detection efficiency curve as a function of size for different saturator temperatures, obtained using ammonium sulfate aerosol.

(HR-DMA; Kangasluoma et al., 2016). By setting the HRDMA to a fixed voltage, we selected a narrow mobility band and simultaneously scanned the nRDMA voltage through its accessible mobility range. The detector used after the HR-DMA was a TSI 3068B electrometer. The detector used downstream of the nRDMA was a PSM (Airmodus A09), previously calibrated with the same setup. The PSM was operated at $T_{\mathrm{gt}}=4^{\circ} \mathrm{C}, T_{\text {inlet }}=5^{\circ} \mathrm{C}$ and $T_{\mathrm{sat}}=[72-78]^{\circ} \mathrm{C}$.

We measured the particle detection efficiency as a function of size for the PSM at different saturator temperatures (Fig. 8), the transfer functions of the nRDMA (Fig. 9) and the total transmission efficiency of the nRDMA-PSM system. The resolution was determined as $\frac{Z_{\text {peak }}}{\Delta Z_{\mathrm{FWHM}}}$, where $Z_{\text {peak }}$ is the mobility of the peak and $\Delta Z_{\mathrm{FWHM}}$ is the full width at half maximum of the peak (Flagan, 1999). The resolution measured with our method (monodisperse test aerosol and scanning voltage for the DMA to characterize) is also function of the DMA voltage (Jiang et al., 2011a). However, this effect is considered to be small with respect to the measurement uncertainties. The transmission efficiency of the nRDMA presented in this work was calculated as the ratio between the concentration of the test aerosol measured with the electrometer and the concentration measured with the PSM after the nRDMA. The total transmission efficiency at $1.47 \mathrm{~nm}$ was $6.3 \%$. After correcting for the PSM detection efficiency the transmission for the nRDMA was $12 \%$. The resolution for the same size was 5.5 (Fig. 9). The transfer function measurements were used to estimate the number size distribution measured during the CLOUD experiments. The total transmission at $1.47 \mathrm{~nm}$ was $6.3 \%$, corresponding to a transmission for the nRDMA of $12 \%$. The resolution for the same size was 5.5 (Fig. 9). The transfer function measurements are fundamental to retrieving quantitative ion measurements (i.e., number size distribution) and are used to invert the data recorded during the CLOUD experiments.

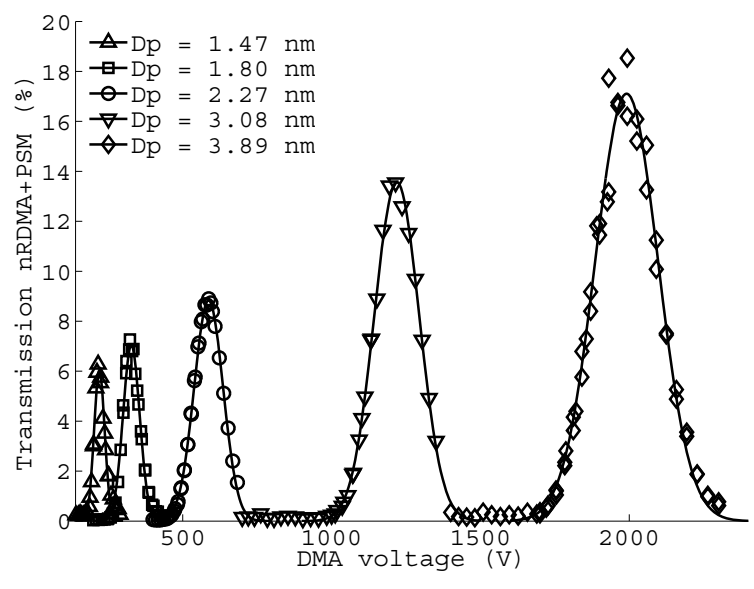

Figure 9. Transfer functions of the nRDMA-PSM system as a function of size. The total transmission at $1.47 \mathrm{~nm}$ was $6.3 \%$, corresponding to a transmission for the nRDMA of $12 \%$. The resolution for the same size was 6 . The experiments were carried out using ammonium sulfate. The temperature of the PSM saturator $T_{\text {sat }}=78^{\circ} \mathrm{C}$; sheath airflow $Q_{\mathrm{sh}}=29 \mathrm{~L} \mathrm{~min}^{-1}$; aerosol flow $Q_{\mathrm{ae}}=2.5 \mathrm{~L} \mathrm{~min}^{-1}$; total inlet flow was $10 \mathrm{~L} \mathrm{~min}^{-1}$.

\subsection{Chamber measurements}

In the CLOUD 7 measurement campaign at CERN, the nRDMA-PSM setup, equipped with the new hightransmission inlet and previously characterized in the laboratory, was used to measure the fraction of charged clusters and ions in the range from 1.3 to $6 \mathrm{~nm}$. The nRDMA was operated in a closed loop. The recirculated sheath flow was cooled to guarantee a sheath gas flow temperature as close as possible to the temperature of the aerosol chamber $(278 \mathrm{~K})$. We calculated the size distribution for the nRDMA-PSM system correcting the raw data for the total transmission. The total transmission and the width of the transfer functions were calculated, making an interpolated curve of the nRDMA transmission and FWHM as a function of voltage, based on the values given in Fig. 9. The data in Fig. 10 show the size distribution $\frac{\mathrm{d} N}{\mathrm{~d} D_{\mathrm{p}}}$ calculated by inverting nRDMA data (Knutson and Whitby, 1975; Reischl, 1991; Jiang et al., 2011a) as follow:

$\frac{\mathrm{d} N(Z)}{\mathrm{d} Z}=N_{\text {counter }}\left(Z^{*}\right) \times \Omega\left(Z, Z^{*}\right)^{-1} \times \epsilon_{\text {counter }}(Z)$,

where $N_{\text {counter }}\left(Z^{*}\right)$ are the raw counts from the PSM + CPC for the centroid mobility $Z^{*}, \Omega\left(Z, Z^{*}\right)^{-1}$ is the inverse of the transfer function matrix and $\epsilon_{\text {counter }}$ is the detection efficiency of the PSM + CPC.

$\frac{\mathrm{d} N(Z)}{\mathrm{d} Z}$ was then converted into $\frac{\mathrm{d} N\left(D_{\mathrm{p}}\right)}{\operatorname{dlog}_{10}\left(D_{\mathrm{p}}\right)}$ by multiplying it by $\frac{\mathrm{d} Z}{\operatorname{dlog}_{10}\left(D_{\mathrm{p}}\right)}$.

As shown in Fig. 10, the new inlet allows the measurement of ambient atmospheric ions down to $1.3 \mathrm{~nm}$ with a nice 

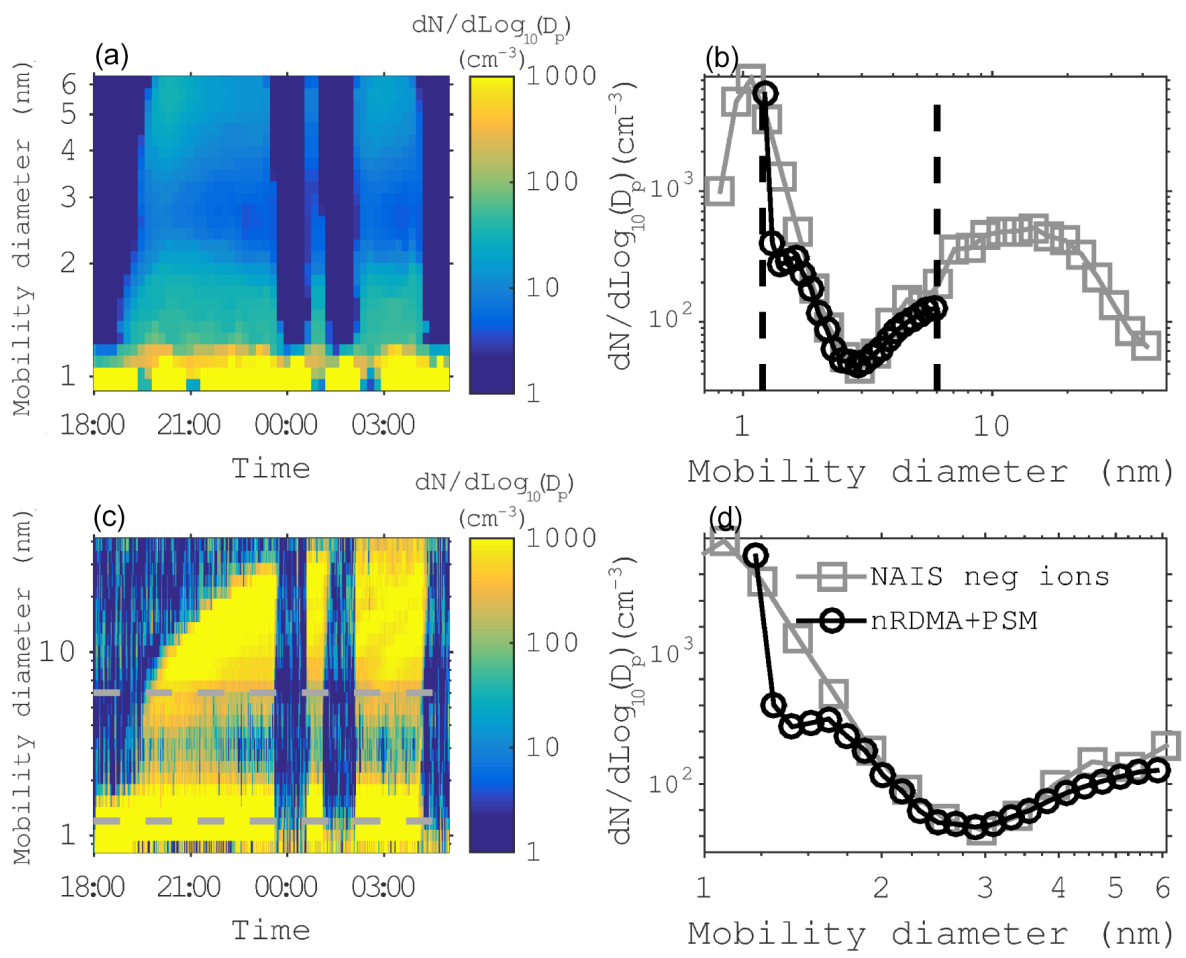

Figure 10. A nucleation experiment during the CLOUD 7 campaign where the high-transmission inlet was used in front of the nRDMA. (a) Measurement of negative ions between 1 and $7 \mathrm{~nm}$ using the nRDMA-PSM system. (c) NAIS negative ion spectrum between 0.8 and $42 \mathrm{~nm}$. Comparison between the size distributions measured with nRDMA-PSM and NAIS (b) in logarithmic scale and (d) with magnified $x$ axis and the $y$ axis in linear scale. Based on the figures, the nRDMA-PSM setup can be used to measure the ions down to $1.3 \mathrm{~nm}$ (dashed line in d). The gaps in the color plot around 00:00 and 02:00 UTC are due to the electric field inside the CLOUD chamber being switched on, causing all the ions in the chamber to be swept out.

agreement with the Neutral cluster and Air Ion Spectrometer (NAIS) negative ion size distribution.

\section{Conclusions}

We reported the successful application of the newly developed high-transmission inlet for the nRDMA. The nRDMAPSM system was tested in the laboratory and in chamber experiments. In this paper we gave an explanation for why it is possible to measure high transmission in laboratory experiments, using the old inlet (Jiang et al., 2011a). We pointed out that the characterization of the old inlet with unipolar ions might not be representative for bipolar conditions during field measurements. We showed experimentally that the transmission increases with time until saturation (Fig. 7), when unipolar, monodisperse ions are used, due to the charge deposition in the insulator. The improvement of the transmission of the nRDMA, using our new inlet, was achieved via the mitigation of the adverse electric field in the inlet region.

The performance of the nRDMA-PSM system, equipped with the new high-transmission inlet, increases the detection of ions with diameters as small as $1.3 \mathrm{~nm}$, achieving a total transmission efficiency of $12 \%$ and a resolution $R$ of
5.5 for ions of mobility $0.97 \times 10^{-4} \mathrm{~m}^{2} \mathrm{~V}^{-1} \mathrm{~s}^{-} 1$, extending the limit of the current technology, which so far has allowed measuring in the same size range, e.g., with the NAIS, with higher total transmission efficiency $(\sim 80 \%)$ but with lower size resolution $(R<2)$, or with the DEG SMPS, with comparable resolution $(R=3.9)$ but with lower total transmission efficiency $(\sim 3 \%)$.

The new inlet now allows the nRDMA-PSM to be used in chamber measurements and in field studies to investigate the onset of new particle formation and to determine formation and growth rates of freshly formed particles with a higher resolution. Recently, two interesting studies showed via experiments (Bezantakos et al., 2015) and theoretically (Tammet, 2015) how, using the same working principle presented in this work, it is possible to create a cost-effective electrostatic filter. To create an ion filter, the magnitudes of the ratio between the flow velocity and the electrostatic velocity have to be much smaller than $1\left(\frac{v_{f}}{v_{E}} \ll 1\right)$, whereas in our hightransmission inlet $\frac{v_{f}}{v_{E}} \gg 1$ (Fig. 6). In their study, Bezantakos et al. (2015) used an electrostatic dissipative material with surface resistivity ranging from $10^{5}$ to $10^{12} \Omega \mathrm{sq}^{-1}$. In a future design of the inlet, a tube made of the same material could replace our segmented tube, making it possible to 
avoid the use of the resistors and improving the robustness and portability of the inlet.

Acknowledgements. This research was funded by the European Commission 7th Framework Programme (Marie Curie Initial Training Network "CLOUD-ITN", grant 215072); the European Research Council (ERC) Advanced Grant Atmospheric nucleation: from molecular to global scale (ATMNUCLE) (grant 227463); from the Austrian Science Fund, FWF (grant number P27295N20); and the Academy of Finland via the Centre of Excellence Programme (projects 1118615 and 272041). Thanks to Rae Ellen Bichell for proofreading.

Edited by: J.-P. Putaud

\section{References}

Almeida, J., Schobesberger, S., Kurten, A., Ortega, I. K., Kupiainen-Maatta, O., Praplan, A. P., Adamov, A., Amorim, A., Bianchi, F., Breitenlechner, M., David, A., Dommen, J., Donahue, N. M., Downard, A., Dunne, E., Duplissy, J., Ehrhart, S., Flagan, R. C., Franchin, A., Guida, R., Hakala, J., Hansel, A., Heinritzi, M., Henschel, H., Jokinen, T., Junninen, H., Kajos, M., Kangasluoma, J., Keskinen, H., Kupc, A., Kurten, T., Kvashin, A. N., Laaksonen, A., Lehtipalo, K., Leiminger, M., Leppa, J., Loukonen, V., Makhmutov, V., Mathot, S., McGrath, M. J., Nieminen, T., Olenius, T., Onnela, A., Petäjä, T., Riccobono, F., Riipinen, I., Rissanen, M., Rondo, L., Ruuskanen, T., Santos, F. D., Sarnela, N., Schallhart, S., Schnitzhofer, R., Seinfeld, J. H., Simon, M., Sipilä, M., Stozhkov, Y., Stratmann, F., Tome, A., Trostl, J., Tsagkogeorgas, G., Vaattovaara, P., Viisanen, Y., Virtanen, A., Vrtala, A., Wagner, P. E., Weingartner, E., Wex, H., Williamson, C., Wimmer, D., Ye, P., Yli-Juuti, T., Carslaw, K. S., Kulmala, M., Curtius, J., Baltensperger, U., Worsnop, D. R., Vehkamaki, H., and Kirkby, J.: Molecular understanding of sulphuric acid-amine particle nucleation in the atmosphere, Nature, 502, 359-363, doi:10.1038/nature12663, 2013.

Asmi, E., Sipilä, M., Manninen, H. E., Vanhanen, J., Lehtipalo, K., Gagné, S., Neitola, K., Mirme, A., Mirme, S., Tamm, E., Uin, J., Komsaare, K., Attoui, M., and Kulmala, M.: Results of the first air ion spectrometer calibration and intercomparison workshop, Atmos. Chem. Phys., 9, 141-154, doi:10.5194/acp-9-141-2009, 2009.

Banin, U., Ben-Shahar, Y., and Vinokurov, K.: Hybrid Semiconductor-Metal Nanoparticles: From Architecture to Function, Chem. Mater., 26, 97-110, doi:10.1021/cm402131n, 2013.

Bezantakos, S., Huang, L., Barmpounis, K., Attoui, M., SchmidtOtt, A., and Biskos, G.: A Cost-Effective Electrostatic Precipitator for Aerosol Nanoparticle Segregation, Aerosol Sci. Tech., 49, iv-vi, doi:10.1080/02786826.2014.1002829, 2015.

Brunelli, N. A., Flagan, R. C., and Giapis, K. P.: Radial Differential Mobility Analyzer for One Nanometer Particle Classification, Aerosol Sci. Tech., 43, 53-59, doi:10.1080/02786820802464302, 2009.
Ehn, M., Thornton, J. A., Kleist, E., Sipilä, M., Junninen, H., Pullinen, I., Springer, M., Rubach, F., Tillmann, R., Lee, B., LopezHilfiker, F., Andres, S., Acir, I.-H., Rissanen, M., Jokinen, T., Schobesberger, S., Kangasluoma, J., Kontkanen, J., Nieminen, T., Kurt'en, T., Nielsen, L. B., Jørgensen, S., Kjaergaard, H. G., Canagaratna, M., Maso, M. D., Berndt, T., Petäjä, T., Wahner, A., Kerminen, V.-M., Kulmala, M., Worsnop, D. R., Wildt, J., and Mentel, T. F.: A large source of low-volatility secondary organic aerosol, Nature, 506, 476-479, doi:10.1038/nature13032, 2014.

Fernandez de la Mora, J. and Kozlowski, J.: Hand-held differential mobility analyzers of high resolution for $1-30 \mathrm{~nm}$ particles: Design and fabrication considerations, J. Aerosol Sci., 57, 45-53, doi:10.1016/j.jaerosci.2012.10.009, 2013.

Flagan, R. C.: History of Electrical Aerosol Measurements, Aerosol Sci. Tech., 28, 301-380, doi:10.1080/02786829808965530, 1998.

Flagan, R. C.: On Differential Mobility Analyzer Resolution, Aerosol Sci. Tech., 30, 556-570, doi:10.1080/027868299304417, 1999.

Gagné, S., Lehtipalo, K., Manninen, H. E., Nieminen, T., Schobesberger, S., Franchin, A., Yli-Juuti, T., Boulon, J., Sonntag, A., Mirme, S., Mirme, A., Hõrrak, U., Petäjä, T., Asmi, E., and Kulmala, M.: Intercomparison of air ion spectrometers: an evaluation of results in varying conditions, Atmos. Meas. Tech., 4, 805-822, doi:10.5194/amt-4-805-2011, 2011.

Iida, K., Stolzenburg, M. R., and McMurry, P. H.: Effect of Working Fluid on Sub-2 nm Particle Detection with a Laminar Flow Ultrafine Condensation Particle Counter, Aerosol Sci. Tech., 43, 81-96, doi:10.1080/02786820802488194, 2009.

IPCC, 2013: Climate Change 2013: The Physical Science Basis, edited by: Stocker, T. F., Qin, D., Plattner, G.-K., Tignor, M., Allen, S. K., Boschung, J., Nauels, A., Xia, Y., Bex, V., and Midgley, P. M., Cambridge University Press, 2013.

Israël, H.: Atmospheric Electricity, vol. I, Fundamentals, conductivity, ions, published for the National Science Foundation by the Israel Program for Scientific Translations, Jerusalem, 317 pp., 1970.

Jiang, J., Attoui, M., Heim, M., Brunelli, N., McMurry, P., Kasper, G., Flagan, R., Giapis, K., and Mouret, G.: Transfer Functions and Penetrations of Five Differential Mobility Analyzers for Sub2 nm Particle Classification, Aerosol Sci. Tech., 45, 480-492, doi:10.1080/02786826.2010.546819, 2011a.

Jiang, J., Chen, M., Kuang, C., Attoui, M., and McMurry, P. H.: Electrical Mobility Spectrometer Using a Diethylene Glycol Condensation Particle Counter for Measurement of Aerosol Size Distributions Down to $1 \mathrm{~nm}$, Aerosol Sci. Tech., 45, 510-521, doi:10.1080/02786826.2010.547538, 2011b.

Jiang, J., Zhao, J., Chen, M., Eisele, F. L., Scheckman, J., Williams, B. J., Kuang, C., and McMurry, P. H.: First Measurements of Neutral Atmospheric Cluster and 1-2 nm Particle Number Size Distributions During Nucleation Events, Aerosol Sci. Tech., 45, ii-v, doi:10.1080/02786826.2010.546817, 2011c.

Kamra, A. K., Siingh, D., Gautam, A. S., Kanawade, V. P., Tripathi, S. N., and Srivastava, A. K.: Atmospheric ions and new particle formation events at a tropical location, Pune, India, Q. J. Roy. Meteor. Soc., 142, 3140-3156, doi:10.1002/qj.2598, 2015.

Kangasluoma, J., Junninen, H., Lehtipalo, K., Mikkila, J., Vanhanen, J., Attoui, M., Sipila, M., Worsnop, D., Kulmala, M., and 
Petaja, T.: Remarks on Ion Generation for CPC Detection Efficiency Studies in Sub-3-nm Size Range, Aerosol Sci. Tech., 47, 556-563, doi:10.1080/02786826.2013.773393, 2013.

Kangasluoma, J., Attoui, M., Korhonen, F., Ahonen, L., Siivola, E., and Petäjä, T.: Characterization of a Herrmann-type highresolution differential mobility analyzer, Aerosol Sci. Tech., 50, 222-229, doi:10.1080/02786826.2016.1142065, 2016.

Kirkby, J., Curtius, J., Almeida, J., Dunne, E., Duplissy, J., Ehrhart, S., Franchin, A., Gagne, S., Ickes, L., Kurten, A., Kupc, A., Metzger, A., Riccobono, F., Rondo, L., Schobesberger, S., Tsagkogeorgas, G., Wimmer, D., Amorim, A., Bianchi, F., Breitenlechner, M., David, A., Dommen, J., Downard, A., Ehn, M., Flagan, R. C., Haider, S., Hansel, A., Hauser, D., Jud, W., Junninen, H., Kreissl, F., Kvashin, A., Laaksonen, A., Lehtipalo, K., Lima, J., Lovejoy, E. R., Makhmutov, V., Mathot, S., Mikkila, J., Minginette, P., Mogo, S., Nieminen, T., Onnela, A., Pereira, P., Petaja, T., Schnitzhofer, R., Seinfeld, J. H., Sipila, M., Stozhkov, Y., Stratmann, F., Tome, A., Vanhanen, J., Viisanen, Y., Vrtala, A., Wagner, P. E., Walther, H., Weingartner, E., Wex, H., Winkler, P. M., Carslaw, K. S., Worsnop, D. R., Baltensperger, U., and Kulmala, M.: Role of sulphuric acid, ammonia and galactic cosmic rays in atmospheric aerosol nucleation, Nature, 476, 429-433, doi:10.1038/nature10343, 2011.

Knutson, E. O. and Whitby, K. T.: Accurate measurement of aerosol electric mobility moments, J. Aerosol Sci., 6, 453-460, doi:10.1016/0021-8502(75)90061-0, 1975.

Kousaka, Y., Okuyama, K., Adachi, M., and Mimura, T.: Effect of Brownian Diffusion on Electrical Classification of Ultrafine Aerosol Particles in Differential Mobility Analyzer, J. Chem. Eng. Jpn, 19, 401-407, doi:10.1252/jcej.19.401, 1986.

Kulmala, M., Riipinen, I., Sipilä, M., Manninen, H. E., Petäjä, T., Junninen, H., Maso, M. D., Mordas, G., Mirme, A., Vana, M., Hirsikko, A., Laakso, L., Harrison, R. M., Hanson, I., Leung, C., Lehtinen, K. E. J., and Kerminen, V.-M.: Toward Direct Measurement of Atmospheric Nucleation, Science, 318, 89-92, doi:10.1126/science.1144124, 2007.

Kulmala, M., Petäjä, T., Nieminen, T., Sipilä, M., Manninen, H. E., Lehtipalo, K., Dal Maso, M., Aalto, P. P., Junninen, H., Paasonen, P., Riipinen, I., Lehtinen, K. E. J., Laaksonen, A., and Kerminen, V.-M.: Measurement of the nucleation of atmospheric aerosol particles, Nat. Protoc., 7, 1651-1667, doi:10.1038/nprot.2012.091, 2012.

Kulmala, M., Kontkanen, J., Junninen, H., Lehtipalo, K., Manninen, H. E., Nieminen, T., Petäjä, T., Sipilä, M., Schobesberger, S., Rantala, P., Franchin, A., Jokinen, T., Järvinen, E., äijälä, M., Kangasluoma, J., Hakala, J., Aalto, P. P., Paasonen, P., Mikkilä, J., Vanhanen, J., Aalto, J., Hakola, H., Makkonen, U., Ruuskanen, T., Mauldin, R. L., Duplissy, J., Vehkamäki, H., Bäck, J., Kortelainen, A., Riipinen, I., Kurt'en, T., Johnston, M. V., Smith, J. N., Ehn, M., Mentel, T. F., Lehtinen, K. E. J., Laaksonen, A., Kerminen, V.-M., and Worsnop, D. R.: Direct Observations of Atmospheric Aerosol Nucleation, Science, 339, $943-$ 946, doi:10.1126/science.1227385, 2013.

Labowsky, M. and Fernandez de la Mora, J.: Novel ion mobility analyzers and filters, J. Aerosol Sci., 37, 340-362, doi:10.1016/j.jaerosci.2005.07.001, 2006.

Lehtipalo, K., Leppa, J., Kontkanen, J., Kangasluoma, J., Franchin, A., Wimnner, D., Schobesberger, S., Junninen, H., Petäjä, T., Sipilä, M., Mikkilä, J., Vanhanen, J., Worsnop, D. R., and Kul- mala, M.: Methods for determining particle size distribution and growth rates between 1 and $3 \mathrm{~nm}$ using the Particle Size Magnifier, Boreal Environ. Res., 19, 215-236, 2014.

Mäkelä, J. M., Riihelä, M., Ukkonen, A., Jokinen, V., and Keskinen, J.: Comparison of mobility equivalent diameter with KelvinThomson diameter using ion mobility data, J. Chem. Phys., 105, 1562-1571, doi:10.1063/1.472017, 1996.

Manninen, H. E., Franchin, A., Schobesberger, S., Hirsikko, A., Hakala, J., Skromulis, A., Kangasluoma, J., Ehn, M., Junninen, H., Mirme, A., Mirme, S., Sipilä, M., Petäjä, T., Worsnop, D. R., and Kulmala, M.: Characterisation of corona-generated ions used in a Neutral cluster and Air Ion Spectrometer (NAIS), Atmos. Meas. Tech., 4, 2767-2776, doi:10.5194/amt-4-2767-2011, 2011.

Mauderly, J. L. and Chow, J. C.: Health Effects of Organic Aerosols, Inhalation Toxicology, 20, 257-288, doi:10.1080/08958370701866008, 2008.

McMurry, P. H., Woo, K. S., Weber, R., Chen, D.-R., and Pui, D. Y. H.: Size distributions of 3-10 nm atmospheric particles: implications for nucleation mechanisms, Philos. T. R. Soc. S.-A, 358, 2625-2642, doi:10.1098/rsta.2000.0673, 2000.

Merikanto, J., Spracklen, D. V., Mann, G. W., Pickering, S. J., and Carslaw, K. S.: Impact of nucleation on global CCN, Atmos. Chem. Phys., 9, 8601-8616, doi:10.5194/acp-9-8601-2009, 2009.

Mirme, S. and Mirme, A.: The mathematical principles and design of the NAIS - a spectrometer for the measurement of cluster ion and nanometer aerosol size distributions, Atmos. Meas. Tech., 6, 1061-1071, doi:10.5194/amt-6-1061-2013, 2013.

Okuyama, K., Kousaka, Y., and Motouchi, T.: Condensational Growth of Ultrafine Aerosol Particles in a New Particle Size Magnifier, Aerosol Sci. Tech., 3, 353-366, doi:10.1080/02786828408959024, 1984.

Paasonen, P., Asmi, A., Petäjä, T., Kajos, M. K., äijälä, M., Junninen, H., Holst, T., Abbatt, J. P. D., Arneth, A., Birmili, W., van der Gon, H. D., Hamed, A., Hoffer, A., Laakso, L., Laaksonen, A., Richard Leaitch, W., Plass-Dülmer, C., Pryor, S. C., Räisänen, P., Swietlicki, E., Wiedensohler, A., Worsnop, D. R., Kerminen, V.-M., and Kulmala, M.: Warming-induced increase in aerosol number concentration likely to moderate climate change, Nat. Geosci., 6, 438-442, doi:10.1038/ngeo1800, 2013.

Petäjä, T., Sipilä, M., Paasonen, P., Nieminen, T., Kurt'en, T., Ortega, I. K., Stratmann, F., Vehkamäki, H., Berndt, T., and Kulmala, M.: Experimental Observation of Strongly Bound Dimers of Sulfuric Acid: Application to Nucleation in the Atmosphere, Phys. Rev. Lett., 106, 228302, doi:10.1103/PhysRevLett.106.228302, 2011.

Reischl, G. P.: The relationship of input and output aerosol characteristics for an ideal differential mobility analyser particle standard, J. Aerosol Sci., 22, 297-312, doi:10.1016/S00218502(05)80008-4, 1991.

Riccobono, F., Rondo, L., Sipilä, M., Barmet, P., Curtius, J., Dommen, J., Ehn, M., Ehrhart, S., Kulmala, M., Kürten, A., Mikkilä, J., Paasonen, P., Petäjä, T., Weingartner, E., and Baltensperger, U.: Contribution of sulfuric acid and oxidized organic compounds to particle formation and growth, Atmos. Chem. Phys., 12, 9427-9439, doi:10.5194/acp-12-9427-2012, 2012.

Riccobono, F., Schobesberger, S., Scott, C. E., Dommen, J., Ortega, I. K., Rondo, L., Almeida, J., Amorim, A., Bianchi, F., Breiten- 
lechner, M., David, A., Downard, A., Dunne, E. M., Duplissy, J., Ehrhart, S., Flagan, R. C., Franchin, A., Hansel, A., Junninen, H., Kajos, M., Keskinen, H., Kupc, A., Kürten, A., Kvashin, A. N., Laaksonen, A., Lehtipalo, K., Makhmutov, V., Mathot, S., Nieminen, T., Onnela, A., Petäjä, T., Praplan, A. P., Santos, F. D., Schallhart, S., Seinfeld, J. H., Sipilä, M., Spracklen, D. V., Stozhkov, Y., Stratmann, F., Tom'e, A., Tsagkogeorgas, G., Vaattovaara, P., Viisanen, Y., Vrtala, A., Wagner, P. E., Weingartner, E., Wex, H., Wimmer, D., Carslaw, K. S., Curtius, J., Donahue, N. M., Kirkby, J., Kulmala, M., Worsnop, D. R., and Baltensperger, U.: Oxidation Products of Biogenic Emissions Contribute to Nucleation of Atmospheric Particles, Science, 344, 717-721, doi:10.1126/science.1243527, 2014.

Rohr, A. C. and Wyzga, R. E.: Attributing health effects to individual particulate matter constituents, Atmos. Environ., 62, 130152, doi:10.1016/j.atmosenv.2012.07.036, 2012.

Rosell-Llompart, J., Loscertales, I. G., Bingham, D., and Fernandez de la Mora, J.: Sizing nanoparticles and ions with a short differential mobility analyzer, J. Aerosol Sci., 27, 695-719, doi:10.1016/0021-8502(96)00016-X, 1996.

Rosser, S. and Fernandez de la Mora, J.: Vienna-Type DMA of High Resolution and High Flow Rate, Aerosol Sci. Tech., 39, 11911200, doi:10.1080/02786820500444820, 2005.

Schauermann, S., Nilius, N., Shaikhutdinov, S., and Freund, H.-J.: Nanoparticles for Heterogeneous Catalysis: New Mechanistic Insights, Accounts Chem. Res., 46, 1673-1681, doi:10.1021/ar300225s, 2012.

Seto, T., Okuyama, K., Juan, L. d., and Fernandez de la Mora, J.: Condensation of supersaturated vapors on monovalent and divalent ions of varying size, J. Chem. Phys., 107, 1576-1585, doi:10.1063/1.474510, 1997.

Sgro, L. A. and Fernandez de la Mora, J.: A Simple Turbulent Mixing CNC for Charged Particle Detection Down to $1.2 \mathrm{~nm}$, Aerosol Sci. Tech., 38, 1-11, doi:10.1080/02786820490247560, 2004.

Siingh, D., Gautam, A. S., Kamra, A. K., and Komsaare, K.: Nucleation events for the formation of charged aerosol particles at a tropical station - Preliminary results, Atmos. Res., 132-133, 239-252, doi:10.1016/j.atmosres.2013.05.024, 2013.

Sipilä, M., Berndt, T., Petäjä, T., Brus, D., Vanhanen, J., Stratmann, F., Patokoski, J., Mauldin, R. L., Hyvärinen, A.P., Lihavainen, H., and Kulmala, M.: The Role of Sulfuric Acid in Atmospheric Nucleation, Science, 327, 1243-1246, doi:10.1126/science.1180315, 2010.

Spracklen, D. V., Carslaw, K. S., Kulmala, M., Kerminen, V.-M., Sihto, S.-L., Riipinen, I., Merikanto, J., Mann, G. W., Chipperfield, M. P., Wiedensohler, A., Birmili, W., and Lihavainen, H.: Contribution of particle formation to global cloud condensation nuclei concentrations, Geophys. Res. Lett., 35, L06808, doi:10.1029/2007GL033038, 2008.
Steiner, G. and Reischl, G. P.: The effect of carrier gas contaminants on the charging probability of aerosols under bipolar charging conditions, J. Aerosol Sci., 54, 21-31, doi:10.1016/j.jaerosci.2012.07.008, 2012.

Steiner, G., Attoui, M., Wimmer, D., and Reischl, G. P.: A Medium Flow, High-Resolution Vienna DMA Running in Recirculating Mode, Aerosol Sci. Tech., 44, 308-315, doi:10.1080/02786821003636763, 2010.

Tammet, H.: Continuous scanning of the mobility and size distribution of charged clusters and nanometer particles in atmospheric air and the Balanced Scanning Mobility Analyzer BSMA, Atmos. Res., 82, 523-535, doi:10.1016/j.atmosres.2006.02.009, 2006.

Tammet, H.: Symmetric Inclined Grid Mobility Analyzer for the Measurement of Charged Clusters and Fine Nanoparticles in Atmospheric Air, Aerosol Sci. Tech., 45, 468-479, doi:10.1080/02786826.2010.546818, 2011.

Tammet, H.: Passage of Charged Particles Through Segmented Axial-Field Tubes, Aerosol Sci. Tech., 49, 220-228, doi:10.1080/02786826.2015.1018986, 2015.

Tammet, H. F.: The Aspiration Method For The Determination Of Atmospheric-IonSpectra, Israel Program for Scientific Translations, 00123, 1970.

Ude, S. and Ferandez de la Mora, J.: Molecular monodisperse mobility and mass standards from electrosprays of tetraalkyl ammonium halides, J. Aerosol Sci., 36, 1224-1237, doi:10.1016/j.jaerosci.2005.02.009, 2005.

Vanhanen, J., Mikkilä, J., Lehtipalo, K., Sipilä, M., Manninen, H. E., Siivola, E., Petäjä, T., and Kulmala, M.: Particle Size Magnifier for Nano-CN Detection, Aerosol Sci. Tech., 45, 533-542, doi:10.1080/02786826.2010.547889, 2011.

Wiedensohler, A.: An approximation of the bipolar charge distribution for particles in the submicron size range, J. Aerosol Sci., 19, 387-389, doi:10.1016/0021-8502(88)90278-9, 1988.

Wimmer, D., Lehtipalo, K., Franchin, A., Kangasluoma, J., Kreissl, F., Kürten, A., Kupc, A., Metzger, A., Mikkilä, J., Petäjä, T., Riccobono, F., Vanhanen, J., Kulmala, M., and Curtius, J.: Performance of diethylene glycol-based particle counters in the sub-3 nm size range, Atmos. Meas. Tech., 6, 1793-1804, doi:10.5194/amt-6-1793-2013, 2013.

Zhang, S. H. and Flagan, R. C.: Resolution of the radial differential mobility analyzer for ultrafine particles, J. Aerosol Sci., 27, 1179-1200, doi:10.1016/0021-8502(96)00036-5, 1996.

Zhang, S.-H., Akutsu, Y., Russell, L. M., Flagan, R. C., and Seinfeld, J. H.: Radial Differential Mobility Analyzer, Aerosol Sci. Tech., 23, 357-372, doi:10.1080/02786829508965320, 1995. 